\title{
sciendo
}

Transport and Telecommunication, 2021, volume 22, no. 1, 109-115

Transport and Telecommunication Institute, Lomonosova 1, Riga, LV-1019, Latvia

DOI 10.2478/ttj-2021-0009

\section{EXPLORING THE EFFECTS OF PSYCHOLOGICAL FACTORS ON THE USE OF NAVIGATION SYSTEMS WHILE DRIVING}

\author{
Nikoletta Ntasiou ${ }^{1}$, Giannis Adamos ${ }^{2}$, Eftihia Nathanail ${ }^{3}$ \\ University of Thessaly, Department of Civil Engineering \\ Pedion Areos, GR-38334 Volos, Greece \\ 'nintasiou@hotmail.com \\ ${ }^{2}$ giadamos@civ.uth.gr \\ 3enath@uth.gr
}

\begin{abstract}
The ever-increasing use of private vehicles makes Advanced Driver Assistance Systems (ADAS) more necessary as they improve users' convenience, safety and travel time. Although these systems offer significant advantages, they call into question the traditional role of users, making the psychology of drivers towards these technologies a necessary factor for their adoption. The purpose of this paper is to investigate the effects of psychological factors on the use of one of the most widely used ADAS, the Global Navigation Satellite Systems (GNSS). Towards this direction, a literature review was conducted to identify the factors that influence drivers' behavior and the psychology of drivers towards new technologies. Furthermore, a questionnaire survey was organized in Greece, based on the Theory of Planned Behavior, including additional variables, which were identified in the literature, such as technophilia, trust in technology and endorsement. From the data collected, models predicting the behavior of drivers were developed through structural equation modelling, concerning the use of navigation systems in both urban and interurban networks. The findings of the research reveal that the intention to use a navigation system is determined by various factors such as behavioral beliefs about its usage, normative beliefs and technophilia. The actual use of a navigation system depends to some extent on this intention.
\end{abstract}

Keywords: Advanced Driver Assistance Systems; sustainability; exploratory factor analysis; structural equation models; user survey

\section{Introduction}

Private vehicle remains one of the most popular means of transport, as well as an indicator of a person's social status and image (Moody \& Zhao, 2019). Despite the availability of several alternative sustainable modes of transport, still a high number of travelers prefer using their own cars, resulting at risky and offensive driving behaviors and consequently traffic accidents.

Advanced Driver Assistance Systems (ADAS), which can improve road safety by avoiding or mitigating collisions, are becoming increasingly popular and they are integrated into new car models. Although these systems provide safety advantages and better driver performance, they question the traditional role of the driver in operating a vehicle. Therefore, drivers' acceptance and their attitude towards these technologies are indispensable factors for their proper use. According to Regan et al. (2002), usefulness, effectiveness, affordability, ease of use and social acceptance are the main components for technology acceptance.

Many research studies have been conducted in the previous years on drivers' acceptance and invehicle technologies, including ADAS. In general, studies evaluating the effects of ADAS on driving behavior can be divided into two categories: simulation experiments and field operational studies (Lyu et al., 2010). In both cases, the effectiveness of ADAS on the improvement of drivers' behavior and performance can be assessed, taking into consideration the roadway network, but also demographics, such as age, gender, driving experience, etc.

Acknowledging that ADAS, and especially navigation systems, have a positive influence on traffic safety and they can provide information that improves the quality of the selected route in terms of traveling time, kilometers traveled, fuel consumption, environmental impacts and trip costs (as in Rooijen et al., 2008), the aim of this paper is to investigate the psychological factors that affect the use of navigation systems. In order to draw useful and reliable conclusions on this topic, a systematic literature review and a structured questionnaire survey were carried out, focusing on Global Positioning Systems (GPS).

The rest of the paper is structured as follows: section 2 presents the theoretical framework, section 3 includes the methodological approach and data analysis, followed by results in section 4 . Section 5 summarizes the main findings of this research. 


\section{Theoretical framework}

One of the most popular behavioral models used to understand drivers' acceptance is the Theory of Planned Behavior (TPB), developed by Ajzen (1991). In general, this theory associates behavior with attitude and intention, addressing also the effect of social norms, when predicting human behavior. According to Ajzen (1991), TPB assumes that there are three independent determinants of intention. The first factor is the attitude towards the behavior and refers to the degree to which a person has a favorable or unfavorable assessment of that behavior (attitude). The second factor consists of the subjective rule, which refers to the perception of social pressure to perform the behavior or not (subjective norm). The third factor is the degree of perceived control, which refers to the perceived ease or difficulty of performing the behavior and reflects the experience of the past, as well as the expected obstacles (perceived behavioral control). As a general rule, the more favorable the attitude and subjective norm towards a behavior and the greater the perceived behavioral control, the stronger a person's intention to perform the behavior is (Ajzen, 1991).

In addition to the factors suggested by TPB, several researchers have investigated other factors that may affect driver's acceptance of ADAS. Based on the findings of the literature review, three additional factors are proposed that affect the driver's acceptance in relation with behavioral intention, which are trust in technology (trust), willingness to promote the use of ADAS (endorsement) and familiarity with technology (technophilia).

Trust: Confidence in a driver assistance system can be defined as the person's belief that the system will perform its intended purpose with high efficiency. While some studies have provided empirical evidence of its predictive potential (as in Ghazizadeh et al., 2012), Kidd et al. (2017) and Rahman et al. (2018) did not report any effect of trust in the drivers' intention to use ADAS.

Endorsement: This factor can be defined as the willingness to approve or recommend the purchase and/or use of a driver assistance system. In general, the willingness to promote such systems has been reported to be high. Ervin et al. (2005) stated that $90 \%$ of the sample of their survey showed willingness to recommend the cruise control system to someone of their environment. Nodine et al. (2011) revealed that 15 of the 18 participants of their survey would recommend to their company to buy trucks equipped with a complete driver assistance system. Rahman et al. (2018) also found that the willingness to promote is an important factor influencing the intention to use ADAS.

Technophilia: The term technophilia refers to the attitude towards technology and the interest and ability of a person to handle innovative technologies (Seebauer and Berger, 2010). Dastjerdi et al. (2019a) proved that people more familiar with technology than others were more likely to use a new driver assistance application. In addition, Seebauer et al. (2015) found that technophilia is an important factor in the willingness to adopt ADAS.

Acknowledging that trust, endorsement and technophilia affect directly drivers' intention towards adopting ADAS, a modified version of Ajen's (1991) TPB is proposed in this paper, in order to formulate the appropriate variables of the questionnaire (Figure 1).

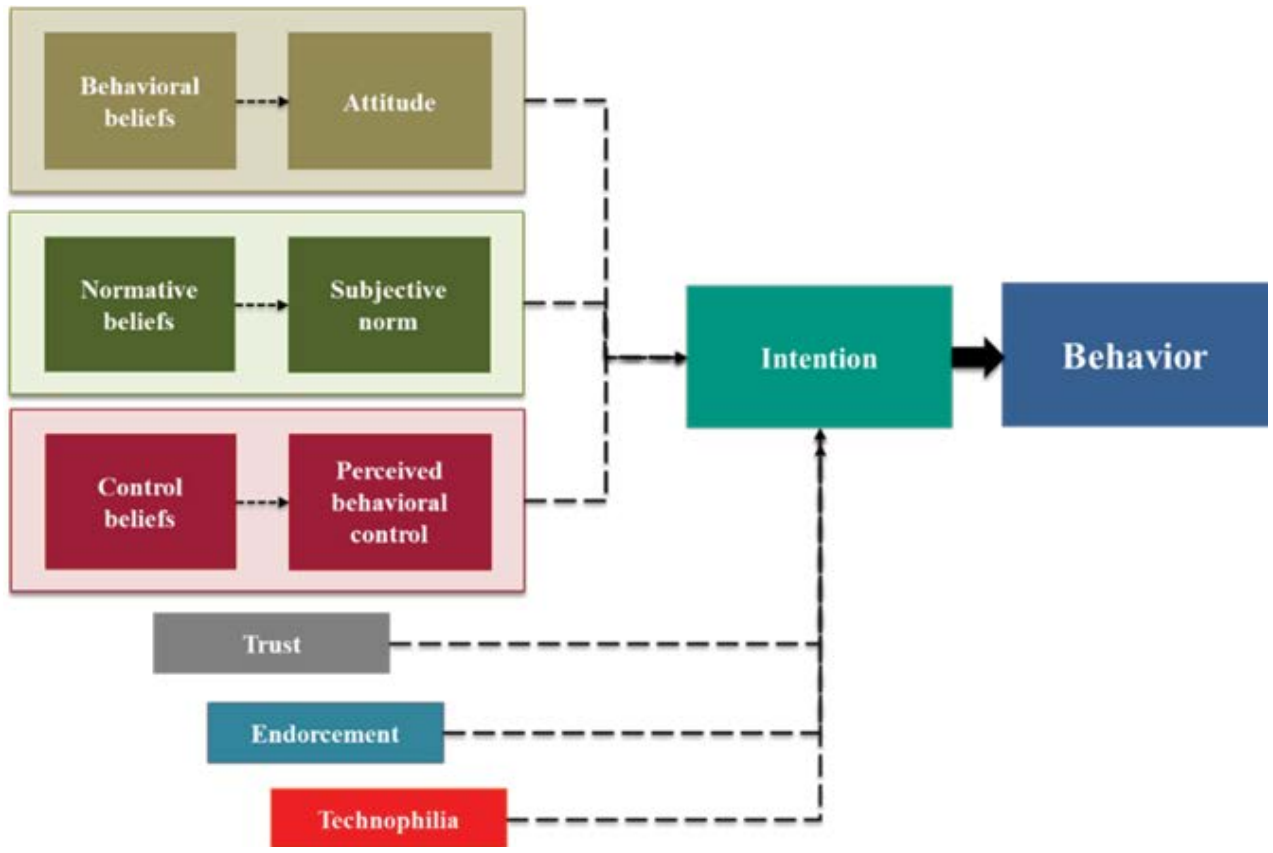

Figure 1. Modified version of Ajzen's (1991) TPB 


\section{Survey design and data processing}

In order to capture drivers' perceptions about ADAS and indicate which psychological factors influence their intention to use navigation systems in urban and interurban environment, a questionnaire survey was organized in Greece by the Traffic, Transportation and Logistics Laboratory (TTLog) of University of Thessaly.

The developed questionnaire considered the modified behavioral model; firstly, the variables of TPB (Ajzen, 1991), attitude, subjective norm and perceived behavioral control, measured through behavioral beliefs, normative beliefs and control beliefs, respectively; secondly, trust, endorsement and technophilia as new components of the modified behavioral model. The questionnaire included 21 questions in total, organized in three parts. The first part referred to ADAS in general, i.e. respondents' familiarity with these systems, the frequency they use navigation systems in the city and in long-distance traveling, etc. The second part focused on psychological factors that affect the use of navigation systems and the third part collected demographic characteristics. The core part of the questionnaire was responded using a 5-point scale, ranging from 1 (strongly disagree/very unlikely/not at all/never) to 5 (strongly agree/very likely/a lot/always), depending on the topic addressed.

The questionnaire was available on SurveyMonkey from April 30, 2019 to July 4, 2019, for individuals throughout Greece. It was distributed through Social Media and emails. It is noted, that data collection was anonymous and in compliance with the European Union's General Data Protection Regulation (GDPR). TTLog values the privacy of respondents, keeps the collected data safe and protected from unauthorized access and refrains from sharing any personal information with third parties.

Descriptive and inferential statistical analyses were conducted with the use of EXCEL and IBM SPPS Statistics programs. A confidence level of 95\% and confidence interval of 5\% were assumed. Exploratory Factor Analysis (EFA) and Confirmatory Factor Analysis (CFA) were also applied, feeding the structural equation modelling procedure, which was performed through the AMOS program. The purpose of EFA is to identify the underlying constructs for a set of measured variables in the absence of previous assumptions, while the CFA aims to test how well the data match a hypothetical measurement model (Dastjerdi et al., 2019b).

\section{Results}

\subsection{Sample profiles}

The final sample was 256 drivers, consisting of $59 \%$ women and $41 \%$ men. The majority of participants are up to 25 years old $(42 \%), 31 \%$ of them are older than 41 years old and the remaining of them are up to 40 years old $(27 \%)$. In addition, most of the respondents $(71 \%)$ are highly educated, $28 \%$ of them have received a secondary level of education and the remaining $1 \%$ are primarily educated. As far as employment status is concerned, it was observed that $56 \%$ of the participants are employed, $39 \%$ students, $3 \%$ unemployed and the remaining $2 \%$ stated a different status. $41,5 \%$ of the respondents have a monthly net-income between $1.001-1.500 €, 32,5 \%$ less than $1.000 €$ and the remaining $26 \%$ greater than $1.500 €$.

Focusing on trip purpose at city level, it was observed that most of the participants $(48,4 \%)$ travel for work, $21,1 \%$ for leisure, $18,4 \%$ for education and the remaining $12,1 \%$ for other purposes. Outside the city grid, most of the participants $(53,5 \%)$ travel for holidays, $23,8 \%$ travel to visit family, $21,1 \%$ travel for work and the remaining $1,6 \%$ for other reasons. The majority of travelers $(70 \%)$ use navigation through their mobile phones, $21 \%$ own a portable GPS system and the remaining $9 \%$ have an in-vehicle system.

\subsection{Exploratory Factor Analysis (EFA)}

All variables of the modified behavioral model, including the TPB variables, trust, technophilia and endorsement were obtained by exploratory factor analysis (EFA). EFA was applied to expose the underlying structure of the variables and investigate the theoretical constructs.

As shown in Tables 1 and 2, all six factors have a reliability coefficient (Cronbach's alpha a) greater than 0,7 (Miller, 1995), good internal consistence with total scale $a=0,89$, as well as good sampling adequacy with Kaiser-Meyer-Olkin $(\mathrm{KMO})=0,87$, suggesting that the questionnaire is reliable and data are suitable for factor analysis. Only the factor addressing endorsement was below the standard $(a=0,29)$ and was omitted from the rest of tests. The factor that expresses the habits of the social environment was simply acceptable, since it is above the "criterion of use" 0,6 (Peterson, 1994). Based on the "two-indicator-factor" mentioned by Bollen (1989), the model is well defined by at least two indicators per factor, if the model has two or more factors. 
The Bartlett's test for sphericity rejected the null hypothesis of an identity correlation matrix. Maximum likelihood with orthogonal "Varimax" rotation generated the four factors of the TPB model (behavioral beliefs (BB), control beliefs $(\mathrm{C})$, normative beliefs $(\mathrm{N})$, intention (I)) as well as two of the extra factors (trust $(\mathrm{R})$ and technophilia $(\mathrm{T})$ ). The variables E1 ("I plan to recommend using a navigation system to my relatives and friends") and E2 ("I am willing to pay for more specialized functionalities of the navigation system"), which were initially considered to describe the factor "endorsement (E)" do not ultimately have a high correlation. However, the variable E1 has a high correlation with the variables describing "intention", resulting in its inclusion in this factor. Focusing on the generated factors, the loadings of the dominant items and their descriptions are presented in Tables 1 and 2 . The cut off of 0,4 (Dastjerdi et al., 2019a, b) was set to retain a set of items representing the factors, so the variables BB4, C3, N1 were rejected from the model.

Table 1. Rotated factor matrix for the TPB variables

\begin{tabular}{|c|c|c|c|c|}
\hline Factor & $\begin{array}{l}\text { Cronbach's } \\
\text { Alpha }\end{array}$ & Item & Coding & Factor loadings \\
\hline \multirow{5}{*}{$\begin{array}{l}\text { Behavioral } \\
\text { Beliefs (BB) }\end{array}$} & \multirow{5}{*}{0,78} & I think it is very useful to use a navigation system while driving & BB1 & 0,525 \\
\hline & & The navigation system makes my trip more efficient & BB2 & 0,768 \\
\hline & & $\begin{array}{l}\text { The navigation system makes it easier not to waste time driving } \\
\text { in the wrong direction }\end{array}$ & BB3 & 0,679 \\
\hline & & The navigation system helps me drive more steadily & BB4 & 0,330 \\
\hline & & $\begin{array}{l}\text { The navigation system gives me a sense of security rather than } \\
\text { nervousness }\end{array}$ & BB5 & 0,454 \\
\hline \multirow{3}{*}{ Intention (I) } & \multirow{3}{*}{0,79} & I plan on continuing to use a navigation system in the future & I1 & 0,698 \\
\hline & & I will try to use a navigation system in the future & $\mathrm{I} 2$ & 0,777 \\
\hline & & $\begin{array}{l}\text { I plan to recommend using a navigation system to my relatives } \\
\text { and friends }\end{array}$ & E1 & 0,531 \\
\hline \multirow{3}{*}{$\begin{array}{l}\text { Control } \\
\text { Beliefs }(C)\end{array}$} & \multirow{3}{*}{0,75} & For me, it's easy to use a navigation system while driving & $\mathrm{C} 1$ & 0,780 \\
\hline & & $\begin{array}{l}\text { I think I have the skills to use a navigation system without } \\
\text { distracting myself from driving }\end{array}$ & $\mathrm{C} 2$ & 0,754 \\
\hline & & $\begin{array}{l}\text { I think I have the ability to get to my destination properly with } \\
\text { guidance from the navigation system }\end{array}$ & $\mathrm{C} 3$ & 0,397 \\
\hline \multirow{3}{*}{$\begin{array}{l}\text { Normative } \\
\text { Beliefs }(N)\end{array}$} & \multirow{3}{*}{0,66} & Most people around me use a navigation system while driving & N1 & 0,391 \\
\hline & & $\begin{array}{l}\text { My family supports me in using a navigation system while } \\
\text { driving }\end{array}$ & $\mathrm{N} 2$ & 0,704 \\
\hline & & $\begin{array}{l}\text { My friends / colleagues / classmates support me in using a } \\
\text { navigation system while driving. }\end{array}$ & N3 & 0,675 \\
\hline
\end{tabular}

Table 2. Rotated factor matrix for factors $\mathrm{T}, \mathrm{R}$

\begin{tabular}{|c|c|c|c|c|}
\hline Factor & $\begin{array}{l}\text { Cronbach's } \\
\text { Alpha }\end{array}$ & Item & Coding & $\begin{array}{l}\text { Factor } \\
\text { loadings }\end{array}$ \\
\hline \multirow{3}{*}{ Technophilia (T) } & \multirow{3}{*}{0,73} & I know how to use such systems very well & $\mathrm{T} 1$ & 0,456 \\
\hline & & Advanced ADAS excite me & $\mathrm{T} 2$ & 0,796 \\
\hline & & I am very interested in ADAS & $\mathrm{T} 3$ & 0,828 \\
\hline \multirow{3}{*}{ Trust (R) } & \multirow{3}{*}{0,83} & I trust the information provided by the navigation system & $\mathrm{R} 1$ & 0,892 \\
\hline & & I consider GPS a reliable navigation system & $\mathrm{R} 3$ & 0,862 \\
\hline & & $\begin{array}{l}\text { I find that the information provided by the navigation } \\
\text { systems is not helpful }\end{array}$ & $\mathrm{R} 3$ & 0,603 \\
\hline
\end{tabular}

\subsection{Confirmatory Factor Analysis (CFA)}

The EFA results were then used to create a measurement model, through AMOS, for conducting a Confirmatory Factor Analysis (CFA), supplementary to EFA. The model was considered satisfactory, as most of the fit indices are within the allowable limits (Hooper et al., 2008; Hox et al., 1998; Iacobucci, 2010). 
In particular the Root Mean Square Error of Approximation-RMSEA $=0,054<0,08$, the Comparative Fit Index-CFI $=0,958 \geq 0,90$ and the Standardized Root Mean Square Residual-SRMR $=0,05<0,08$. The Goodness of Fit-GFI =0,924 and the Normed Fit Index-NFI =0,908, thus close to the threshold of 0,95. Table 3 shows the standard parameter estimates, the critical ratios (C.R.) (which are calculated by dividing the parameter estimation by the standard error) and the $p$-value. It is observed that estimates of the variables for measuring the latent factors are all statistically significant, which improves the structural validity of the proposed model.

Table 3. Estimates of the measurement equations of the latent constructs

\begin{tabular}{|c|c|c|c|c|}
\hline Factor & Item & Est. & C.R. & p-value \\
\hline \multirow{4}{*}{$\begin{array}{l}\text { Behavioral Beliefs } \\
\text { (BB) }\end{array}$} & BB1 & 0,844 & 11,163 & $* * *$ \\
\hline & BB2 & 1,000 & - & - \\
\hline & BB3 & 0,853 & 10,989 & $* * *$ \\
\hline & BB5 & 0,937 & 9,708 & $* * *$ \\
\hline \multirow{2}{*}{ Control Beliefs (C) } & $\mathrm{C} 1$ & 1,000 & - & - \\
\hline & $\mathrm{C} 2$ & 0,732 & 8,596 & $* * *$ \\
\hline \multirow{2}{*}{ Normative Beliefs (N) } & N2 & 1,000 & - & - \\
\hline & N3 & 0,995 & 7,149 & $* * *$ \\
\hline \multirow{3}{*}{ Technophilia (T) } & $\mathrm{T} 1$ & 0,670 & 7,645 & $* * *$ \\
\hline & $\mathrm{T} 2$ & 1,000 & - & - \\
\hline & $\mathrm{T} 3$ & 0,967 & 11,001 & $* * *$ \\
\hline \multirow{3}{*}{ Trust (R) } & $\mathrm{R} 1$ & 1,000 & - & - \\
\hline & $\mathrm{R} 2$ & 0,989 & 16,887 & $* * *$ \\
\hline & R3 & 0,794 & 10,444 & $* * *$ \\
\hline \multirow{3}{*}{ Intention (I) } & I1 & 0,840 & 12,315 & $* * *$ \\
\hline & I2 & 1,000 & - & - \\
\hline & E1 & 0,837 & 10,548 & $* * *$ \\
\hline
\end{tabular}

\subsection{Structural Equation Modelling (SEM)}

Based on the results of EFA and CFA, two models were developed, one addressing drivers' behavior at city level (frequency of using a navigation system in the city in the last year) and one for drivers' behavior at intercity level (frequency of using a navigation system for trips outside the city in the last year), which are coded as model B1 and B2, respectively. In order to ensure compatibility between the developed models and collected data, the $\chi^{2}$ test and the previously explained fit indices were used.

Focusing on $\mathrm{B} 1$, results showed that even if the $\chi^{2}$ test remained significant $\left(\chi^{2} / \mathrm{df}=1,6\right.$, $\mathrm{p}$-value $<0,01)$, the rest fit indices supported acceptance model fit (RMSEA $=0,05, \mathrm{GFI}=0,92$, $\mathrm{CFI}=0,96, \mathrm{NFI}=0,90, \mathrm{SRMR}=0,049)$. As illustrated in Figure 2, intention (I) $(\beta=0,22, \mathrm{p}$-value $<0,05)$ and technophilia $(\mathrm{T})(\beta=0,18, \mathrm{p}$-value $<0,05)$ significantly predict drivers' behavior towards navigation system use. From the TPB variables, it is observed that behavioral beliefs (BB) and normative beliefs (N) significantly influence travellers' intention. $\mathrm{BB}(\beta=0,5$, $\mathrm{p}$-value $<0,001)$ has the strongest influence on intention, followed by $\mathrm{N}(\beta=0,23, \mathrm{p}$-value $<0,001)$. On the other hand, the influence coefficient of control beliefs $(C)$ on intention is non-significant $(\beta=-0,1$, p-value $>0,05)$, meaning that drivers' skills or easiness to use navigation systems does not affect their intention to adopt such a system. It is also indicated that technophilia $(\beta=0,33, \mathrm{p}$-value $<0,001)$ significantly affects intention, while trust in technology $(\mathrm{R})$ seems not to influence significantly travellers' intention to use navigation systems $(\beta=-0,05$, $\mathrm{p}$-value $>0,05)$. Summing up, the squared multiple correlation of intention is $61 \%$, measuring adequately the percent of variance explained by BB, C, N, T and R. The squared multiple correlation of behavior towards using navigation systems is $13 \%$, measuring the respective percent of variance explained by intention and familiarity with technology. 


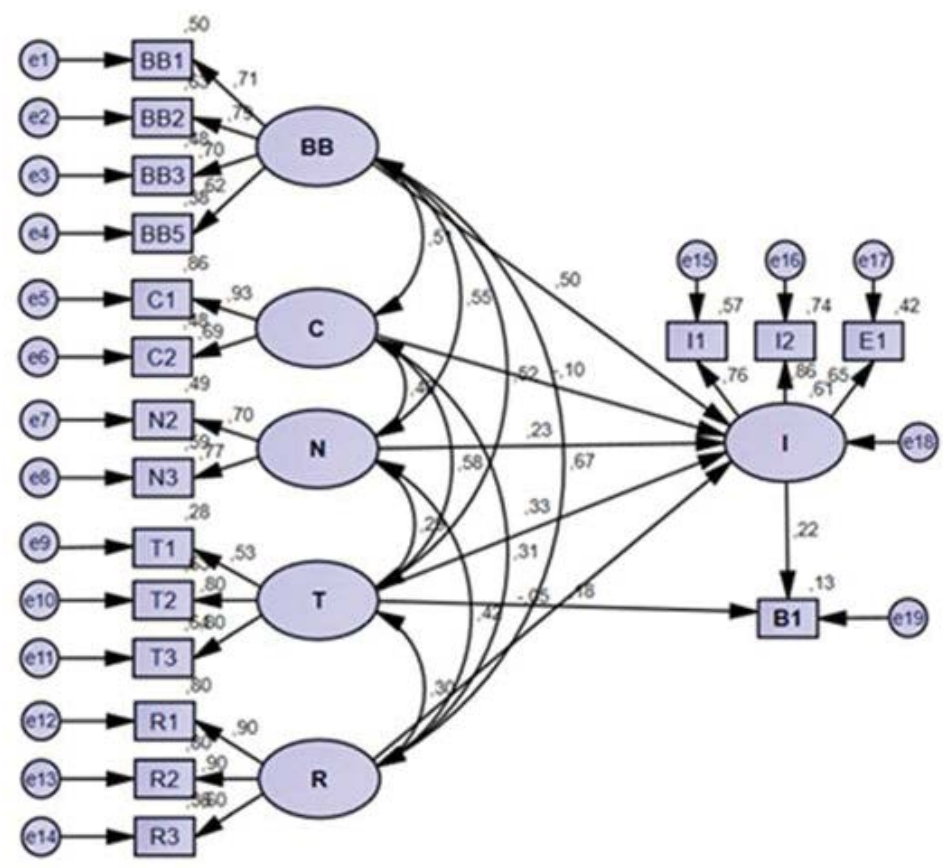

Figure 2. Model B1 (travel behavior at city level)

Similar findings were revealed, when studying drivers' behavior (B2) at intercity level (Figure 3). Results showed that regardless that $\chi^{2}$ test remained significant $\left(\chi^{2} / \mathrm{df}=1,9, \mathrm{p}\right.$-value $\left.<0,01\right)$, the rest fit indices supported acceptance model fit $(\mathrm{RMSEA}=0,06, \mathrm{GFI}=0,91, \mathrm{CFI}=0,94, \mathrm{NFI}=0,89, \mathrm{SRMR}=0,054)$. As presented in Figure 3, intention (I) $(\beta=0,32$, p-value $<0,05)$ significantly predicts drivers' behavior towards navigation system use. On the other hand, the effect of technophilia (T) on intention is not statistically significant $(\beta=0,08$, $\mathrm{p}$-value $>0,05)$. Behavioral beliefs are the strongest predictor of intention $(\beta=0,51, \mathrm{p}$-value $<0,001)$, then technophilia $(\beta=0,32, \mathrm{p}$-value $<0,001)$ and lastly normative beliefs $(\beta=0,25, \mathrm{p}$-value $<0,01)$. In this case, the squared multiple correlation of intention is $62 \%$, measuring adequately the percent of variance explained by BB, $\mathrm{C}, \mathrm{N}, \mathrm{T}$ and R. The squared multiple correlation of behavior towards using navigation systems is $14 \%$, measuring the respective percent of variance explained by intention and technophilia.

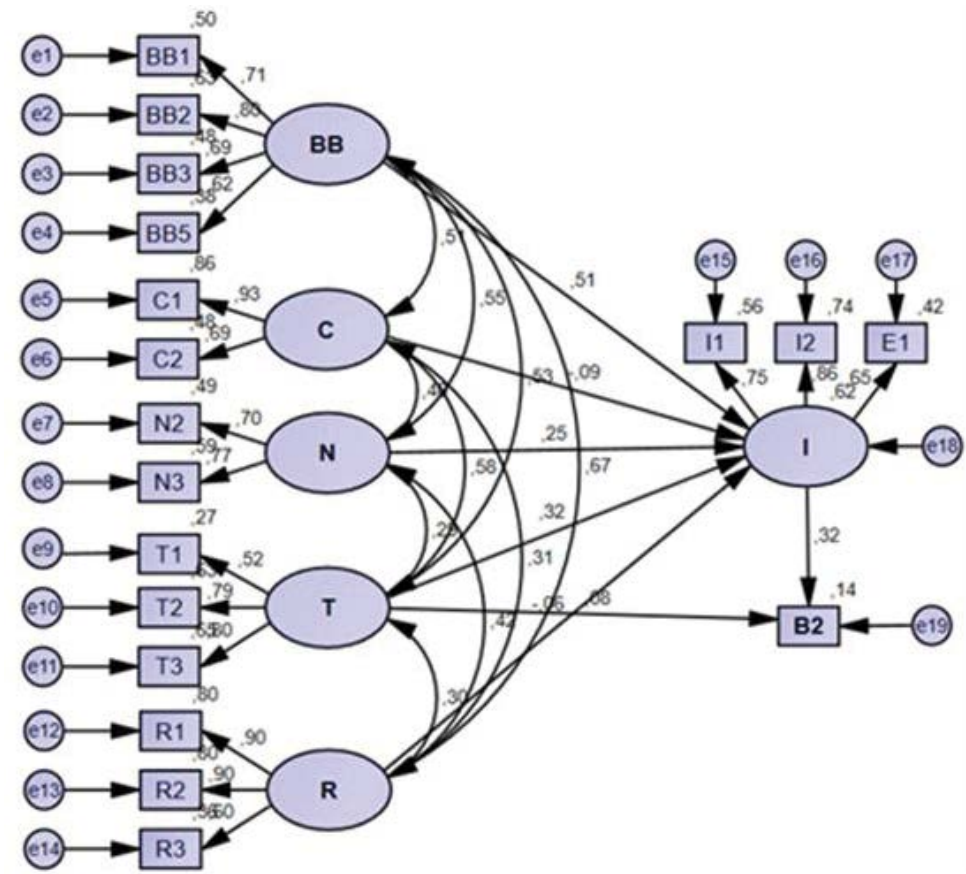

Figure 3. Model B2 (travel behavior at intercity level) 


\section{Conclusions}

The main findings of this research reveal that drivers' behavior towards navigation system use is influenced significantly by their intention to adopt such assistance systems, both at city and intercity level. It was also validated that TPB's behavioral beliefs are strong predictors of intention. Regarding the additional factors investigated in this study, it was observed that technophilia is a strong predictor of drivers' intention and consequently behavior towards the adoption of navigation systems, while trust in technology and endorsement seem not to significantly affect their behavior.

\section{References}

1. Ajzen, I. (1991) The theory of planed behavior. Organizational Behavior and Human Decision Processes, 50, 179-211.

2. Bollen, K.A. (1989) Structural equations with latent variables. Canada Wiley.

3. Dastjerdi, A.M., Kaplan, S., Silva, J. de A., Nielsen, O.A. \& Pereira, F.C. (2019a) Use intention of mobility-management travel apps: The role of users goals, technophile attitude and community trust. Transportation Research Part A, 126, 114-135.

4. Dastjerdi, A.M., Kaplan, S., Silva, J. de A., Nielsen, O.A. \& Pereira, F.C. (2019b) Participating in environmental loyalty program with a real-time multimodal travel app: User needs, environmental and privacy motivators. Transportation Research Part D, 67, 223-243.

5. Ervin, R., Sayer, J., LeBlanc, D., Bogard, S., Mefford, M., Hagan, M., Winkler, C. (2005) Automotive Collision Avoidance System Field Operational Test Report: Methodology and Results (No. HS-809 900).

6. Ghazizadeh, M., Peng, Y., Lee, J.D., Boyle, L.N. (2012) Augmenting the technology acceptance model with trust: commercial drivers' attitudes towards monitoring and feedback. Proceedings of the Human Factors and Ergonomic Society Annual Meeting, 56(1), pp. 2286-2290, Sage Publications.

7. Hooper, D., Coughlan, J. and Mullen, M. R. (2008) Structural Equation Modelling: Guidelines for Determining Model Fit. The Electronic Journal of Business Research Methods, 6(1), 53-60.

8. Hox, J.J. \& Bechger, T.M. (1989) An introduction to structural equation modeling. Family Science Review, 11, 354-373.

9. Iacobucci, D. (2010) Structural equations modeling: Fit Indices, sample size, and advanced topics. Journal of Consumer Psychology, 20(1), 90-98.

10. Kidd, D.G., Cicchino, J.B., Reagan, I.J. \& Kerfoot, L.B. (2017) Driver trust in five driver assistance technologies following real-world use in four production vehicles. Traffic Inj. Prev., 18 (sup1), S44-S50.

11. Lyu, N., Deng, C., Xie, L., Wu, C., \& Duan, Z. (2018) A field operational test in China: Exploring the effect of an advanced driver assistance system on driving performance and braking behavior. Transportation Research Part F: Traffic Psychology and Behaviour, 65, 730-747.

12. Miller, M. B. (1995) Coefficient alpha: A basic introduction from the perspectives of classical test theory and structural equation modeling. Structural Equation Modeling, 2, 255-273.

13. Moody, J., \& Zhao, J. (2019) Car pride and its bidirectional relations with car ownership: Case studies in New York City and Houston. Transportation Research Part A: Policy and Practice, 124, 334-353.

14. Nodine, E., Lam, A., Najm, W., Wilson, B., Brewer, J. (2011). Integrated Vehicle-Based Safety Systems Heavy-Truck Field Operational Test Independent Evaluation (No. HS-811 464).

15. Peterson, R. A. (1994). A Meta-Analysis of Cronbach's Coefficient Alpha. Journal of Consumer Research, 21, 381-391.

16. Regan, M., Mitsopoulos, E., Haworth, N., \& Young, K. (2002). Acceptability of in-vehicle intelligent transport systems to Victorian car drivers. Melbourne, Australia: Monash University Accident Research Centre.

17. Rooijen, Tariq \& Vonk, T. \& Hogema, Jeroen \& Feenstra, P. (2008) The impact of navigation systems on traffic safety. 15th World Congress on Intelligent Transport Systems and ITS America Annual Meeting, pp. 6122-6134.

18. Seebauer, S., Berger, M. (2010) Willingness to use advanced traveler information systems in Austria. In: $13^{\text {th }}$ International IEEE Conference on Intelligent Transportation Systems. IEEE, pp. 1831-1836.

19. Seebauer, S., Stolz, R., \& Berger, M. (2015) Technophilia as a driver for using advanced traveler information systems. Transportation Research Part C: Emerging Technologies, 60, 498-510. 